\title{
Empreendedorismo sustentável em regiões turísticas de Goiás
}

\author{
Sustainable entrepreneurship in tourist regions of Goiás (Brazil) \\ Thaynara Santiago Pereira, Cândido Borges
}

\begin{abstract}
RESUMO
O objetivo deste artigo é compreender o processo de criação de empresas por empreendedores que exploram o nicho da sustentabilidade e os principais desafios que eles encontram nesse processo. $O$ artigo apresenta os resultados de uma pesquisa qualitativa e exploratória em que cinco casos de empresas localizadas em duas regiões turísticas de Goiás - Pirenópolis e Chapada dos Veadeiros - foram analisados. Como quadro de análise foi utilizado um modelo que estrutura o processo de criação em quatro etapas: iniciação, preparação, lançamento e consolidação. Os dados primários foram coletados por meio de entrevistas com os empreendedores. Os resultados obtidos apontam a ausência de motivação exclusivamente financeira dos empreendedores, a ausência de práticas estruturadas de planejamento e a adoção de práticas de responsabilidade ambiental acompanhada, em alguns casos, de responsabilidade social. As principais dificuldades encontradas pelos empreendedores na criação da empresa foram agrupadas em três categorias: dificuldades com serviços ou políticas públicas, dificuldades relacionadas ao processo logístico ou de produção, dificuldades relacionadas à falta de planejamento. O presente artigo contribui para facilitar e estimular a ação dos empreendedores que pretendem criar negócios sustentáveis, assim como os gestores públicos, responsáveis por políticas de apoio a esse tipo de empreendedorismo.
\end{abstract}

PALAVRAS-CHAVE: Empreendedorismo Sustentável; Turismo; Processo de Criação de Empresas.

\begin{abstract}
The aim of this article is to understand the process of business creation by entrepreneurs who explore the sustainability niche and to identify the main challenges they face in this process. The article presents the results of a qualitative study in which five cases of companies located in two tourist regions of Goiás - Pirenópolis and Chapada dos Veadeiros - were analysed. A model which structures the creation process in four stages (initiation, preparation, launch and consolidation) was used as framework for this analysis. The primary data were collected through interviews with the entrepreneurs. The results obtained indicate a lack of exclusively financial motivation on the part of the entrepreneurs, the absence of structured planning practices and the adoption of environmentally responsible together with, in some cases, socially responsible practices. The main difficulties which the entrepreneurs encountered in the creation of the companies were grouped into three categories: difficulties with public services, difficulties related to the logistical or production processes and difficulties related to the lack of planning. The present article seeks to facilitate and to stimulate the activities of entrepreneurs who aim to create sustainable businesses as well as the public officials responsible for implementing policies to support this type of entrepreneurship.
\end{abstract}

KEYWORDS: Sustainable Entrepreneurship; Tourism; New Venture Creation Process.

Página 758 Revista Brasileira de Ecoturismo, São Paulo, v.6, n.3, ago/out 2013, pp.758-777.

Sociedade Brasileira de Ecoturismo. Rua Dona Ana, 138, Vila Mariana, São Paulo, SP - Brasil. E-mail: rbecotur@sbecotur.org.br; Tel. (55-II) 99196-7685 


\section{Introdução}

O surgimento do tema sustentabilidade relacionado ao desenvolvimento econômico ocorreu ao longo do século XX, a partir da percepção de que os recursos despendidos no intensivo padrão de produção e consumo eram finitos e que não subsistiriam (NASCIMENTO, 2012). Alguns dos grandes marcos que simbolizam essa percepção são a Conferência de Estocolmo, em 1972, o relatório Brundtland, em 1987 e a Eco-92 (MORETTO; GIACCHINI, 2005; NASCIMENTO, 2012). Essas discussões atingem o mundo corporativo, se concretizando em temas como gestão ambiental e responsabilidade social, e o desenvolvimento sustentável passa a ser abordado não como um problema, mas como algo possível e necessário (MELO; COHEN, 2009).

Dessa forma, uma nova lógica de produção vem sendo institucionalizada e as organizações passam a inovar atendendo às três dimensões da sustentabilidade social, ambiental e econômica (BARBIERI et al., 2010). Com base nessas dimensões, que constituem o modelo Triple Bottom Line (ELKINGTON, 1998), organizações sustentáveis são aquelas que conseguem atuar perduravelmente, se relacionando bem com a sociedade e minimizando riscos (SCHARF, 2004).

Dentro desse contexto, a literatura define como empreendedorismo sustentável a criação de organizações baseadas nesse tripé (social, ambiental e econômico), ou ainda a criação de empresas que simplesmente explorem o nicho da sustentabilidade (BORGES et al., 2011).

No que tange ao empreendedorismo, no Brasil, há ainda poucos estudos deste tema voltados à área de turismo (TEIXEIRA, 2012). Se essa temática de uma forma geral já apresenta limites na literatura, estes são ainda maiores quando inserimos o tema sustentabilidade na discussão. Frente a esta lacuna, este artigo tem como objetivo compreender como os empreendedores que exploram o nicho da sustentabilidade realizam as principais atividades do processo de criação de empresas e identificar quais são os principais desafios desses empreendedores nesse processo.

A maior compreensão das atividades que os empreendedores realizam no processo de criação de novas empresas sustentáveis, incluindo seus obstáculos, pode ajudar os futuros empreendedores a trilhar com maior facilidade o caminho na criação de negócios que exploram o nicho da sustentabilidade. Pode ainda auxiliar os gestores públicos e as pessoas e organizações que apoiam o empreendedorismo a melhor formular e implementar políticas de apoio a empreendedorismo sustentável. Estimular a geração de iniciativas empreendedoras sustentáveis pode contribuir para que um número cada vez maior de organizações atue de forma efetivamente sustentável, onde o tripé social-econômico-ambiental seja respeitado.

Antes de apresentar a metodologia utilizada na pesquisa, será apresentado, na próxima seção, o referencial teórico da pesquisa. Na seção seguinte serão apresentados os resultados da análise. E na última seção, a conclusão do trabalho, com suas principais contribuições e sugestões para futuras pesquisas. 


\section{Fundamentação teórica}

\section{Empreendedorismo}

O empreendedorismo é um processo que passa pela identificação, avaliação e exploração de uma oportunidade de ação (SHANE; VENKATARAMAN, 2000). Ele envolve a capacidade humana de se favorecer moldando as condições do ambiente através de um processo de criação de uma nova realidade (COSTA, 2008).

Melo Meto e Froes (2002) ressaltam o papel do empreendedorismo no desenvolvimento local. Para estes autores, nos moldes atuais, existem quatro correntes de estudos do empreendedorismo, e uma delas se preocupa com as questões do desenvolvimento local. Ainda segundo Melo e Froes (2002), o empreendedorismo designa os estudos relativos ao universo de atuação dos empreendedores, seus perfis, sistemas de atividades e origens.

O empreendedor é o principal agente do empreendedorismo. Para Filion (1999), o empreendedor é uma pessoa criativa, que objetiva a inovação e possui um alto nível de consciência ambiental da qual se utiliza para detectar oportunidades de negócio. De acordo com Schaltegger (2002), o empreendedor pode ser interpretado como aquele que toma a iniciativa para "construir pontes", como um catalisador que reúne dinheiro, pessoas, ideias e recursos.

No que diz respeito aos estudos relativos a empreendedorismo e empreendedores, percebe-se na atualidade uma segmentação do tema, de forma a facilitar sua interpretação. Já se fala em empreendedorismo tecnológico (SHANE, 2001), empreendedorismo cultural (DEHEINZELIN, 2006; LIMEIRA, 2008), empreendedorismo por mulheres (MACHADO et al., 2003), empreendedorismo social (MAIR; MARTI, 2006) e empreendedorismo ambiental ou ecoempreendedorismo (SCHALTEGGER, 2002; DIXON; CLIFFORD, 2007), sendo que estes dois últimos podem ser considerados precursores e elementos constituintes do emergente empreendedorismo sustentável (HOCKERTS; WUSTENHAGEN, 2010; PARRISH, 2007).

O empreendedorismo sustentável, segundo Boszczowski e Teixeira (2009), surge por meio de estudos envolvendo meio ambiente, responsabilidade social e negócios, como resposta a uma necessidade das empresas de mudarem suas práticas sociais e ambientais. Para as autoras, o empreendedorismo sustentável pode ser entendido como uma função da produção, de forma que "seu principal objetivo seria produzir bens e serviços que atuem nas soluções dos problemas da sociedade" (BOSZCZOWSKI; TEIXEIRA, 2009, p.11). Boszczowski e Teixeira (2009) afirmam ainda que as oportunidades de negócios sustentáveis podem ser caracterizadas como as oportunidades que proporcionam aos empreendedores possíveis soluções para falhas de mercado relevantes ao meio ambiente, aumentando o bem estar social e promovendo o desenvolvimento sustentável social. Essa visão está de acordo com o conceito de Shepherd e Patzelt (2011, p.142, tradução nossa):

Empreendedorismo sustentável é focado na preservação da natureza, no suporte à vida e à comunidade, em busca de perceber oportunida- 
des para trazer à existência futura produtos, processos e serviços para o ganho, onde o ganho é amplamente interpretado de forma a incluir os ganhos econômicos e não econômicos para os indivíduos, a economia e a sociedade.

Young e Tilley (2006), em congruência com o modelo Triple Bottom Line (ELKINGTON, 1998), afirmam que o empreendedorismo sustentável engloba três dimensões do empreendedorismo - econômica, social e ambiental. Pimentel, Reinaldo e Oliveira (2010) resumem as três dimensões preconizadas por Young e Tilley (2006) da seguinte forma (Quadro 1):

Quadro 1: Dimensões do empreendedorismo sustentável.

Chart 1: Dimensions of sustainable entrepreneurship.

\begin{tabular}{|l|l|}
\hline Dimensão do Empreendedorismo econômico & $\begin{array}{l}\text { empreender com o objetivo de desenvolver uma ativi- } \\
\text { dade que gere lucro. Refere-se à capacidade da em- } \\
\text { presa de manter-se viva, de ser um negócio autossus- } \\
\text { tentável. }\end{array}$ \\
\hline Dimensão do Empreendedorismo Social & $\begin{array}{l}\text { empreender com o objetivo de gerar valores sociais e } \\
\text { culturais de maneira criativa e inovadora. }\end{array}$ \\
\hline $\begin{array}{l}\text { Dimensão do Empreendedorismo Ecológico ou Am- } \\
\text { biental }\end{array}$ & $\begin{array}{l}\text { empreender utilizando estratégias de negócio proati- } \\
\text { vas e ecologicamente orientadas, redefinindo sua } \\
\text { cultura e suas relações sociais. }\end{array}$ \\
\hline
\end{tabular}

Fonte: Adaptado de Pimentel, Reinaldo e Oliveira (2010, p. 7-8).

Source: Adapted from Pimentel, Reinaldo e Oliveira (2010, p. 7-8).

Para Borges et al. (2011) o empreendedorismo sustentável também tem ligação com o empreendedorismo social e o ambiental. E essa ideia é reforçada através da sugestão de uma tipologia para o empreendedorismo sustentável, de acordo com o Quadro 2 a seguir:

Quadro 2: Tipos de empreendedorismo sustentável.

Chart 2: Types of sustainable entrepreneurship.

\begin{tabular}{|c|c|}
\hline Indicador & Tipo \\
\hline Nicho da sustentabilidade explorado & $\begin{array}{c}\text { Negócio ambiental } \\
\text { Negócio social }\end{array}$ \\
\hline Papel da sustentabilidade & $\begin{array}{c}\text { Sustentabilidade como meio } \\
\text { Sustentabilidade como objetivo }\end{array}$ \\
\hline Uso da responsabilidade social empresarial & $\begin{array}{c}\text { Com responsabilidade social empresarial } \\
\text { Sem responsabilidade social empresarial }\end{array}$ \\
\hline
\end{tabular}

Fonte: Borges et al. (2011, p. 5).

Source: Borges et al. (2011, p. 5).

De acordo com o quadro, o empreendedorismo sustentável pode abranger diversos tipos, variando em função de determinados indicadores. O primeiro indicador é o nicho de sustentabilidade explorado, que pode determinar se o negócio é um tipo de 
negócio ambiental ou social. Segundo os autores, o negócio ambiental está relacionado a produtos, serviços e processos que atuam no sentido de internalizar, minimizar ou se antecipar às externalidades ambientais, e podem ser divididos em quatro categorias: a) produtos ecoeficientes; b) turismo e lazer na natureza. c) agricultura orgânica e extrativismo; e d) reciclagem e reutilização. O negócio social, para Borges et al. (2011), aborda produtos e serviços que melhorem as condições e a qualidade de vida de grupos socialmente desfavorecidos.

O segundo indicador relaciona-se ao papel da sustentabilidade, ou seja, se as ações sustentáveis foram realizadas como um objetivo ou como um meio:

Para uns, o objetivo principal com o empreendimento é o lucro, e a exploração de um negócio social ou ambiental é o meio utilizado para isso. Para outros, o objetivo é colaborar para o desenvolvimento sustentável, e o lucro proporcionado pelo negócio é apenas um meio de manter uma empresa e um estilo de vida compatível com os valores da sustentabilidade (BORGES et al., 2011, p.7).

O terceiro indicador diz respeito ao uso ou não da responsabilidade social empresarial, que resume a combinação dos termos responsabilidade social e ambiental (BORGES et al., 2011).

\section{O processo de criação de empresas}

O processo de criação de empresas, segundo Hisrich, Peters e Shepherd (2009), é o processo de buscar um novo empreendimento, seja introduzir novos produtos em mercados existentes, de produtos existentes em novos mercados, e/ou a criação de uma nova organização.

Alguns autores do campo do empreendedorismo, para explicar o complexo e dinâmico processo de criação de uma nova empresa, utilizam-se de modelos, que dividem este processo em etapas, facilitando a compreensão e estudo do fenômeno (BORGES; FILION; SIMARD, 2008). Há, portanto, diferentes modelos que sintetizam as etapas e atividades que se encaixam nesse processo de criação. Um dos modelos propostos é o modelo de Hisrich, Peters e Shepherd (2009).

Para Hisrich, Peters e Shepherd (2009, p.31), "um empreendedor precisa encontrar, avaliar e desenvolver uma oportunidade, superando as forças que resistem à criação de algo novo". Além disso, Hisrich, Peters e Shepherd (2009) afirmam ainda que, embora as fases do processo de criação de uma empresa ocorram progressivamente, nenhuma é tratada isoladamente ou está totalmente concluída antes de ocorrer o trabalho nas outras fases.

Borges, Filion e Simard (2008) também propuseram um modelo, baseado em quatro etapas, com o intuito de desenvolver uma estrutura para facilitar o entendimen- 
to do processo de criação. Assim, combinando as etapas e atividades mais citadas na literatura, os autores elaboraram o seguinte modelo de análise, aqui apresentado em sua forma simplificada (Quadro 3):

Quadro 3: Etapas e atividades do processo de criação.

Chart 3: Steps and activities of the creation process.

\begin{tabular}{|c|c|c|c|c|}
\hline Etapas & Iniciação & Preparação & Lançamento & Consolidação \\
\hline $\begin{array}{c}\text { Ativi- } \\
\text { dades }\end{array}$ & $\begin{array}{c}\text { Identificação da opor- } \\
\text { tunidade de negócio. } \\
\text { Reflexão e desenvolvi- } \\
\text { mento da ideia de } \\
\text { negócio. } \\
\text { Decisão de criar a } \\
\text { empresa. }\end{array}$ & $\begin{array}{c}\text { Redação do plano de } \\
\text { negócios. } \\
\text { Constização de recur- } \\
\text { sos financeiros. } \\
\text { empreendedora. } \\
\text { Constituição legal da } \\
\text { empresa. }\end{array}$ & $\begin{array}{c}\text { Instalação física e de } \\
\text { equipamentos } \\
\text { Desenvolvimento do } \\
\text { primeiro produto ou } \\
\text { serviço. } \\
\text { Contratação de cola- } \\
\text { boradores. } \\
\text { Comercialização e } \\
\text { venda. }\end{array}$ & $\begin{array}{c}\text { Novas rodadas de } \\
\text { financiamento. } \\
\text { Promoção e comer- } \\
\text { cialização. } \\
\text { Operação e produ- } \\
\text { ção. } \\
\text { Gestão da nova } \\
\text { empresa. }\end{array}$ \\
$\begin{array}{c}\text { Alcance do ponto de } \\
\text { equilíbrio }\end{array}$ \\
\hline
\end{tabular}

Fonte: Adaptado de Borges, Filion e Simard (2008).

Source: Adapted from Borges, Filion e Simard (2008).

O modelo de Borges, Filion e Simard foi construído inicialmente para o empreendedorismo tradicional, mas já foi adaptado e utilizado com sucesso no estudo da criação de empreendimentos sociais por Onozato e Teixeira (2008). Dessa forma, ele apresenta potencial para ser utilizado e adaptado para o estudo de empresas sustentáveis.

\section{Método de pesquisa}

A pesquisa foi qualitativa e exploratória, com enfoque indutivo. A estratégia de pesquisa utilizada foi o estudo de casos múltiplos (YIN, 2005). O estudo de caso é uma das muitas maneiras de fazer pesquisa em ciências sociais e segundo Yin (2005) é uma investigação empírica que examina um fenômeno contemporâneo dentro do contexto da vida real, especialmente quando os limites entre este fenômeno e o contexto não estão claramente definidos. Nesta perspectiva, o estudo de caso de natureza qualitativa proporciona uma análise profunda acerca da natureza do objeto em questão - explicar como se desenvolve o processo de criação de empresas sustentáveis.

Dessa forma, foi feito um levantamento de possíveis casos de criação de empresas relacionadas ao empreendedorismo sustentável no estado de Goiás. Os empreendedores das organizações foram contatados por e-mail e telefone e aceitaram participar da pesquisa. Por motivos de confidencialidade, os nomes das organizações e dos empreendedores citados neste artigo são fictícios.

As cinco organizações selecionadas foram: Pousada Pirenópolis; Herbário; Empresa Alimentos Orgânicos; Santuário e Pousada Cavalcante. Em todos os casos o tipo de nicho de sustentabilidade explorado é o ambiental, sendo que a Pousada Pirenópolis, o 
Santuário e a Pousada Cavalcante estão classificados no grupo turismo e lazer na natureza e o Herbário e a Empresa Alimentos Orgânicos como agricultura orgânica e extrativismo. Em ambos os casos a sustentabilidade é concebida como um objetivo pelos empreendedores. No que diz respeito ao uso da responsabilidade social empresarial, há níveis de variação entre os casos abordados, sendo que nos casos da Pousada Cavalcante e da Pousada Pirenópolis é possível observar claramente a aplicação deste conceito e já no caso do Herbário essa prática não está explícita.

Com a intenção de explorar o histórico de criação de cada uma das cinco organizações selecionadas, foram feitas entrevistas em profundidade os empreendedores dos casos escolhidos. Os entrevistados foram: Fabrício Mendonça, da Pousada Pirenópolis; Antônio Silva, do Herbário; José Moura, da empresa Alimentos Orgânicos; André Souza, do Santuário e Sérgio Lemes, da Pousada Cavalcante. O roteiro de entrevista foi definido considerando as atividades do modelo de criação de empresas de Borges, Filion e Simard (2008) - Quadro 3 - e de acordo com a fundamentação teórica onde foram identificadas outras dimensões e temas importantes para a criação de empresas sustentáveis, mas resguardando a abertura para temas emergentes. As entrevistas foram gravadas e posteriormente transcritas.

Além dos dados coletados nas entrevistas, a pesquisa utilizou dados secundários, coletados na internet e nas próprias instituições. As entrevistas e demais dados coletados foram codificados e editados para a construção de tabelas-síntese de cada caso (MILES; HUBERMAN, 1994). Por fim, foram feitas análises intra e inter caso, com o intuito de reconstruir e comparar os processos de criação de cada uma das organizações, detectando as principais dificuldades nesse processo.

\section{Perfil das organizações analisadas}

A Pousada Pirenópolis foi inaugurada em 2003, na cidade de Pirenópolis, pelo empreendedor Fabrício Mendonça, que objetivava aplicar a experiência adquirida em consultoria e gestão de negócios investindo em um negócio ecossustentável. A ideia surgiu a partir da construção de alguns chalés para aluguel, que possibilitaram ao empreendedor a aquisição de conhecimentos voltados à sustentabilidade. Com a compra de um terreno em parceria com amigos, o empreendedor decidiu pela construção da pousada, que atualmente conta com 14 apartamentos, todos construídos a partir da valorização do conforto e segurança aliados à preservação do meio ambiente e dos aspectos socioculturais da comunidade local. Dentre as ações ecológicas e educacionais realizadas pela Pousada Pirenópolis estão: o projeto de reflorestamento ao redor da pousada para compensar a construção do estabelecimento, o reaproveitamento da água das chuvas, a reutilização de tijolos e telhas usadas, a divulgação de informações descritivas de árvores nativas em cada apartamento, o incentivo ao consumo de produtos do Cerrado, bem como a coleta e seleção do lixo reciclável.

O Herbário foi fundado pelo empreendedor Antônio Silva, conhecido como Herbário, que chegou a Alto Paraíso de Goiás em 1988, onde se instalou e fixou residência. Com base na experiência já adquirida em outros estados, o empreendedor decidiu dar continuidade ao trabalho já desenvolvido outrora e em 1990 começou a desenvolver as atividades do Herbário. Os produtos ofertados pelo Herbário, além das ervas medicinais, 
englobam xaropes, garrafadas, pomadas e artesanato indígena. Alguns produtos de artesanato são fabricados pelo próprio empreendedor, em seu ateliê, e outros são comprados diretamente de índios de diversas tribos. Já no que diz respeito à fabricação dos produtos medicinais, esta fica a cargo exclusivamente do empreendedor, que valoriza muito o fator credibilidade. Atualmente, o interesse de Antônio não está ligado a dinheiro, mas sim à tranquilidade de vida, à tradição, por isso ele não deseja expandir o negócio.

A empresa Alimentos Orgânicos, situada na cidade de Pirenópolis, surgiu em 2003 com a ideia de preservação do cerrado e utilização de seus frutos como forma de proporcionar melhoria de vida aos produtores rurais. Foi com base nessa ideia que o empreendedor José Moura e seu sócio desenvolveram o primeiro produto da empresa, naquela época ainda intitulada com outro nome, a barra de cereal com castanha de baru. As primeiras vendas, com o produto ainda em fase de experiência, foram realizadas apenas para amigos. À medida que o produto foi se aprimorando foram surgindo os primeiros clientes. Alguns meses depois do projeto inicial, José Moura decidiu romper a sociedade e foi quando a empresa passou a se chamar Alimentos Orgânicos. A partir daí, o empreendedor começou a desenvolver outras receitas e a negócio foi expandindo. Atualmente entre os produtos produzidos e vendidos pela Alimentos Orgânicos estão barras de cereais, pães, bolos e biscoitos.

Os empreendedores Pedro Souza e Vânia Souza adquiriram o Santuário em 1975, com o intuito de torná-la um pedaço de terra sustentável e assim proporcionar aos filhos qualidade de vida. Perceberam logo a riqueza do local e adotaram metas de preservação e sustentabilidade da propriedade. A comercialização de alguns produtos começou em Brasília, onde o empreendedor havia percebido a existência de demanda por produtos orgânicos. Dessa forma, logo a Fazenda já estava atraindo o interesse de amigos e alguns visitantes. Por volta dos anos 90, pressionados pelo turismo crescente em Pirenópolis, os empreendedores decidiram transformar a área em uma RPPN - Reserva Particular do Patrimônio Natural, e também fazer parcerias. Atualmente ela oferece diversos programas de turismo e educação ambiental envolvendo visitantes eventuais, grupos escolares e segmentos da comunidade de Pirenópolis, além de ter incrementado o Plano de Manejo com pesquisa de fauna e flora e a lista de espécies.

A pousada Cavalcante surgiu em 2002, do desejo do empreendedor Sérgio Lemes de estar mais próximo à natureza, desenvolvendo atividades ligadas a ela. O lugar escoIhido para a instalação do novo empreendimento foi a cidade de Cavalcante, tendo em vista o então potencial turístico da região. Logo no início da construção da pousada, graças a um projeto empreendido pela FUNATURA, a Pousada Cavalcante tornou-se uma RPPN - Reserva Particular do Patrimônio Natural. O lançamento oficial da pousada foi em agosto de 2003, quando toda a estrutura ficou pronta. A divulgação na internet e em revistas de grande circulação, além de parcerias com agências de turismo, foram ações importantes para fortalecer a imagem de empresa.

\section{Análise e discussão dos resultados}

Nesta seção serão apresentadas as principais atividades do processo de criação das empresas estudadas, e as dificuldades que foram detectadas por meio da análise comparativa dos casos. 


\section{Principais atividades do processo de criação}

De acordo com o modelo de Borges, Filion e Simard (2008), adotado como referência, o processo de criação de empresas divide-se em quatro etapas principais: iniciação, preparação, lançamento e consolidação. A seguir serão apresentados os momentos mais críticos dentro dessas etapas principais.

\section{Etapa de iniciação}

Esta etapa trata da identificação da oportunidade e da motivação para criar o negócio.

No caso do empreendedor Fabrício Mendonça, a ideia de criar uma empresa já era vislumbrada pelo empreendedor desde o ano de 1991, quando chegou à cidade de Pirenópolis. Ele almejava aplicar o conhecimento já adquirido com o serviço de consultoria construindo uma empresa que fosse autossuficiente e que possibilitasse ao empreendedor um gerenciamento mais à distância. Além disso, Fabrício, desde os 15 anos, graças ao contato com a mata do campus onde estudava e com o rio Araguaia, já sonhava em trabalhar com algo que estivesse ligado à natureza, ao desenvolvimento sustentável, que gerasse mínimos impactos. Por isso decidiu investir no ramo de hotelaria. Em 1997, surgiu a oportunidade de comprar um terreno em Pirenópolis em sociedade com dois amigos. Na sua parte do terreno, ele construiu a pousada na cidade.

O empreendedor Antônio Silva chegou à cidade de Alto Paraíso em 1988. Graças ao aumento da movimentação turística da cidade e à experiência adquirida em atividades anteriores, em outros estados, é que o trabalho com as ervas tornou-se um negócio. $O$ conhecimento que o empreendedor possui é uma herança de família - desde pequeno ele já estava acostumado a lidar com ervas e plantas e a tratar-se com produtos naturais. As intenções do empreendedor não são prioritariamente financeiras, o que o empreendedor almeja é obter seu sustento de forma tranquila, assim ele afirma: "a minha opção para ficar aqui já era porque era um lugar central no país e um lugar que não tinha progresso, não tinha movimentação de progresso".

José Moura é um dos empreendedores responsáveis pela criação da empresa Alimentos Orgânicos. Ele sempre foi ligado à área de alimentação, em especial a integral e a orgânica e chegou a Pirenópolis em 2001, onde já havia morado alguns anos antes. $\mathrm{Na}$ volta a Pirenópolis passou a fazer pães integrais e, de forma paralela, atuar como representante comercial de alimentos naturais. Logo em seguida, juntamente com um amigo, surgiu a ideia de utilizar o baru como matéria-prima para produção de barras de cereais. A ideia inicial da empresa, que a priori possuía outra denominação, já era pautada na preservação do cerrado e na utilização dos frutos do cerrado para proporcionar melhora de vida para os agricultores e produtores rurais.

A ideia do Santuário foi trazida da Bélgica, onde os empreendedores Pedro Souza e Vânia Souza conheceram uma comunidade alternativa autossustentável. A partir daí, os empreendedores idealizaram um pequeno pedaço de terra que fosse sustentável e que proporcionasse qualidade de vida para seus filhos. Ao comprar a fazenda, por volta dos anos 70 , começou a plantar para o próprio sustento e, graças à paixão pelas plantas, co- 
meçou a comercializar produtos orgânicos, dando origem ao que se tornaria o Santuário. O filho do casal, o empreendedor André, aponta como um dos motivadores que o ajudaram a empreender o curso do EMPRETEC, realizado pelo SEBRAE.

A decisão do engenheiro Sérgio Lemes em empreender no setor de turismo se deu por uma vontade antiga de trabalhar com a natureza, de ter um trabalho de preservação. Ele não se sentia satisfeito com o trabalho que realizava na indústria, ainda que em alguns momentos na área ambiental, e por isso idealizava poder sair da cidade e viver em contato mais próximo com a natureza, desenvolvendo atividades ligadas a ela. $\mathrm{O}$ empreendedor teve então a oportunidade de efetuar esta mudança, e assim surgiu a Pousada Cavalcante.

Pode-se perceber, através da análise dos casos, que em todos eles os empreendedores, de alguma forma, já haviam tido contato bem próximo com a natureza, o que os possibilitou idealizar a criação de um negócio sustentável. Todos almejavam uma melhor qualidade de vida e eram motivados pela paixão e pela vontade de contribuir com o meio. Em nenhum dos casos observa-se empreendedores movidos exclusivamente pelo interesse monetário.

\section{Etapa de preparação}

Esta etapa foca as atividades de planejamento e mobilização de recursos.

O empreendedor Fabrício Mendonça participou de todo o projeto de construção da pousada Pirenópolis. Ele afirma que, apesar de difícil, foi possível construí-la ainda que com pouco capital. Ele contou com o apoio da esposa, que é sócia, para sustentar a casa e investiu todo o dinheiro que possuía na pousada. Os recursos investidos para iniciar a pousada sempre foram próprios, porque, segundo o empreendedor, realizar um empréstimo só é indicado, em caso de hotelaria turística, para expansão, quando já houver clientela garantida e rentabilidade segura.

A principal ferramenta utilizada por Fabrício para obter as informações necessárias para o negócio é a internet. Ele acredita que as informações estão muito disseminadas e acessíveis e que, através dessas informações e de informações compartilhadas com amigos, pode-se criar qualquer coisa.

No caso do herbário, não houve planejamento. O empreendedor foi beneficiado pela movimentação turística da cidade e por ser muito conhecido no trato com plantas medicinais. Além disso, Herbário foi beneficiado também com a doação de um terreno pela prefeitura, que criou um bairro no intuito de expandir comercial e industrialmente a cidade.

A empresa Alimentos Orgânicos foi iniciada com um montante de $R \$ 30,00$, utilizados para compra da matéria prima necessária para a produção das primeiras barrinhas de baru. O empreendedor não faz referência a nenhum tipo de estudo de mercado ou planejamento para abrir a empresa. Mas ele cita que atualmente a pesquisa, o planejamento e o financeiro ficam a cargo principalmente de sua esposa, e que eles efetivamente ocorrem.

O Santuário foi, com o apoio da FUNATURA, uma ONG com sede em Brasília, a primeira RPPN - Reserva Particular do Patrimônio Natural - do estado de Goiás e uma 
das seis primeiras do Brasil. Isso possibilitou à fazenda mobilizar recursos financeiros através do apoio do Governo Britânico e de outras empresas. Ainda assim, grande parte dos recursos adveio dos próprios empreendedores. Houve uma preocupação, por parte dos empreendedores, de compreenderem, desde o início, o que o público, a clientela da região desejava, segundo afirma André Souza:

Porque a gente precisava entender o que esse turista queria da gente, a gente começou a lidar com turismo sem nenhum exemplo, de onde que a gente vai tirar um exemplo de um centro de visitantes? Não tinha! De onde a gente vai tirar uma trilha bem feita dentro de uma mata? Não tinha! Então assim, fomos os pioneiros na história de entender o público de Brasília, que é o nosso principal público, o que ele queria.

No caso da empresa Pousada Cavalcante, é possível perceber que houve uma preocupação no que tange à localização do empreendimento, conforme declara Sérgio Lemes:

(...) pesquisei diversos lugares no país onde poderia estar fazendo esse empreendimento, o objetivo dessa pesquisa era identificar locais onde o turismo, ele não estivesse totalmente estruturado, o objetivo era encontrar um lugar onde a coisa estivesse se desenvolvendo para entrar, não ter que entrar num mercado já saturado, um mercado muito competitivo, ter um diferencial já logo no ingresso.

O empreendedor fez um curso em uma empresa de São Paulo, sobre como montar e gerir uma pousada. Dessa forma, a escolha da propriedade foi previamente pensada e foi desenvolvido um projeto arquitetônico, o que revela certo planejamento por parte do empreendedor, ainda que ele não tenha feito um plano de negócios tradicional. Segundo ele:

(...) foi bem na "unha" mesmo. Óbvio que teve todo o planejamento, o fluxo físico e financeiro para a obra, tudo isso daí eu trouxe um pouco da experiência da indústria e coloquei numa forma um pouco mais simplificada, mas eu tentei fazer isso com algum tipo de critério, mas você pensar num negócio com taxa de retorno, não. Até porque o mercado era insipiente, não existia dados para você fazer qualquer tipo de análise, projeção, qualquer coisa do gênero.

A maior ferramenta de pesquisa para Sérgio é também a internet, ele acredita que a internet é uma fabulosa fonte de informações. Os recursos financeiros investidos inicialmente vieram do próprio empreendedor.

\section{Etapa de lançamento}

Esta etapa abrange a contratação e gestão de recursos humanos assim como o desenvolvimento do produto e as vendas.

A pousada Pirenópolis foi inaugurada no Réveillon de 2003, já com a primeira etapa construída, com uma quitinete e cinco apartamentos. A pousada iniciou com um fun- 
cionário, contratado na própria cidade de Pirenópolis, e o empreendedor, que na época morava em Goiânia, e ia juntamente com a família cuidar da pousada aos finais de semana. Por volta do ano de 2007, o empreendedor mudou-se com sua família para Pirenópolis e a segunda etapa da pousada foi finalizada, que consistiu na construção de um primeiro andar de apartamentos. Em 2009 foram construídos mais quatro apartamentos, totalizando 14 apartamentos. Segundo o empreendedor, todas as atividades dele são baseadas no conceito de permacultura. Por isso, tudo o que hoje há na pousada foi desenvolvido com o intuito de ser ambientalmente sustentável, desde o projeto de reflorestamento ao redor da pousada até a reutilização de tijolos e telhas usadas. Além disso, segundo Fabrício Mendonça:

a pousada cumpre também um papel de educação ambiental: todos os apartamentos têm o nome de árvores do cerrado, que são as árvores que tem no reflorestamento, as árvores nativas. (...) Então o hóspede tem a oportunidade de ver a importância daquela árvore, daquela planta para a humanidade.

O pessoal da pousada Pirenópolis sempre foi formalmente registrado e hoje a pousada possui cinco empregados, contratados na própria região. Além disso, são motivados a se conscientizarem no que tange às questões ambientais: uma das formas de motivação é a participação nos lucros advindos da venda do material reciclável recolhido.

Os primeiros clientes da pousada Pirenópolis foram amigos e as principais ferramentas que contribuíram para o aumento da clientela, segundo o empreendedor, foram a internet e a divulgação boca a boca.

No caso do Herbário, assim que o empreendedor chegou a Alto Paraíso teve que aperfeiçoar seus produtos: a embalagem, o rótulo, a documentação e registro tiveram que ser modificados, por exigências do mercado turístico da região e da vigilância sanitária. Além disso, como cada região tem um tipo de vegetação típica, o empreendedor teve que se adaptar também às ervas daquela região. O Herbário já é, desde a inauguração, formalmente registrado.

O empreendedor do Herbário chega a novas receitas e fórmulas geralmente aprendendo com outras pessoas, além de ler muito participar de encontros voltados a medicina natural. A principal forma de divulgação do empreendedor é a boca a boca.

As primeiras barrinhas da empresa Alimentos Orgânicos, na época com outra denominação, foram feitas com baru e vendidas para amigos porque, segundo o empreendedor, ainda estavam em fase de experiência. A barrinha só começou a ter a forma e o sabor almejados pelo empreendedor depois de algumas tentativas e, a partir daí, ela começou a ser vendida também em Brasília. Assim que o empreendedor desfez a sociedade e mudou o nome da empresa para Alimentos Orgânicos, começou a trabalhar com novos ingredientes, tais como castanha de pequi. E experimentou também novas receitas, produzindo pães, bolos, biscoitos e palitinhos. As novas receitas são elaboradas com base em tentativas e aos poucos vão sendo aperfeiçoadas. O empreendedor José Moura está sempre pesquisando novas ideias, seja na internet ou em conversas com amigos.

A clientela principal da Alimentos Orgânicos são os restaurantes e lojas de produ- 
tos naturais, e a maior parte das vendas destina-se a Brasília. $\mathrm{O}$ empreendedor acredita muita em vendas pela internet, apesar de ainda ter somente alguns clientes on-line. José Moura afirma que as primeiras vendas foram facilitadas pelo fato dele já ter trabalhado antes com a venda de outro produto integral, já possuindo, então, contato com esse tipo de mercado.

Além do empreendedor, a empresa Alimentos Orgânicos conta com mais três funcionários, dentre eles, a esposa e o filho de José Moura. A empresa atualmente ainda é informal, mas José Moura tem a intenção de registrá-la para poder ter acesso a determinados financiamentos e obter recursos suficientes para sanar os gargalos existentes no processo produtivo e logístico.

Os primeiros clientes do Santuário surgiram através das vendas de alguns produtos orgânicos em uma feira na cidade de Brasília, com a empresa ainda informal. À medida que essas vendas foram aumentando, foram crescendo também as vendas realizadas por telefone. Logo os empreendedores receberam a sugestão de transformar a fazenda numa RPPN - Reserva Particular do Patrimônio Natural - e com a transformação surgiram boas parcerias e a estrutura pode ser melhorada. Os primeiros visitantes apareceram após esta etapa, com a inauguração da RPPN em 1991 e a visita do príncipe Philip. Nessa época a empresa já começou a trabalhar com educação ambiental para escolas. Em 2004, o Santuário implantou o arvorismo e em seguida foram inaugurados também o rapel, o salto primata e o pêndulo, que são atividades de aventura, que, depois de um ano de adaptação, foram certificadas pela ABETA - Associação Brasileira das Empresas de Turismo de Aventura. Além disso, a fazenda ficou também conhecida por uma famosa refeição com 45 itens que é servida das $9 \mathrm{~h}$ às $16 \mathrm{~h}$.

No que diz respeito aos funcionários, o Santuário trabalha com 8 diaristas e 3 mensais durante os finais de semana regulares e o número de diaristas aumenta para 14 quando se trata de feriados. A principal ferramenta de divulgação do Santuário hoje é a boca a boca, ainda que haja um site, o empreendedor afirma que não há recursos suficientes para se investir em mídias. Quanto ao desenvolvimento de novos produtos, André afirma que são advindos majoritariamente de sua própria intuição.

A pousada Cavalcante começou oficialmente em agosto de 2003, quando a estrutura física da empresa ficou pronta. Todos os funcionários atuais da empresa são da cidade de Cavalcante, formalizados e totalizam um número de cinco. No começo, o empreendedor afirma ter sido difícil encontrar funcionários qualificados ao ramo, e por causa disso, a empresa tinha um turnover bem alto, que foi sanado graças a políticas implantadas na pousada de valorização da mão de obra, entre elas a política de participação na taxa de serviço, onde é sugerida uma taxa para o hóspede e o valor dessa taxa é distribuído entre os funcionários e a política de hospedar os próprios funcionários, dando a eles, esporadicamente, acesso gratuito aos serviços da pousada.

Para o desenvolvimento de novos produtos, Sérgio cita como uma das fontes o formulário de pesquisa que fica disponível para o hóspede, de onde, segundo ele, surgem algumas boas propostas. Além disso, o empreendedor acredita que viajar e observar o mercado também contribui para a adoção de novas práticas.

A principal ferramenta de divulgação apontada por Sérgio é a internet: a inserção da pousada nos diretórios de busca voltados à hotelaria que existiam na época. Além dis- 
so, ele afirma que a aparição da pousada em um guia de grande circulação e a transformação da área em uma RPPN também contribuíram.

\section{Etapa de consolidação}

A etapa de consolidação diz respeito à sobrevivência, ao crescimento e à gestão da empresa.

O empreendedor Fabrício Mendonça acredita que o fator ambiental, apesar de não ser determinante, é um dos fatores que ajudam a promover a pousada Pirenópolis. Ele afirma que tinha a intenção de desmistificar a associação entre ecologia e baixa qualidade. A ideia dele sempre foi proporcionar ao cliente conforto, qualidade e respeito ao meio ambiente. Segundo ele, esse fator ambiental funciona como uma espécie de filtro, atraindo um público mais exigente. Além disso, segundo Fabrício, por ser considerada uma pousada ecológica, a Pousada Pirenópolis já foi inclusive beneficiada pela geração de mídias espontâneas, o que contribui para o marketing da empresa. Uma das estratégias de gestão da Pousada Pirenópolis para atrair clientes é não aumentar o valor da tarifa nas férias. Fabrício acredita que com essa estratégia ele estará estimulando mais clientes a conhecerem a pousada, é o que ele denominou marketing presencial: fazer com que o cliente experimente o produto, graças à tarifa mais acessível, e assim volte mais vezes.

No que diz respeito à operação, quando ligada ao fator sustentabilidade, segundo Fabrício, esta se torna mais trabalhosa, principalmente na etapa de implantação dos processos, entretanto é também mais barata, já que há muita economia, tais como economia de água, de energia, em adubo, etc. Há ainda benefícios psicológicos, devido à qualidade de vida adquirida. Essa economia advinda de práticas ecologicamente corretas é que proporciona à pousada a possibilidade de manter tarifas abaixo da média. Mesmo sabendo que a empresa possui um diferencial, e que isso possibilitaria a cobrança de um adicional dos clientes, o empreendedor prefere fazer uso da estratégia de diminuir a tarifa e melhorar a taxa de ocupação da pousada. Além dessa, outra estratégia da qual Fabrício faz uso para tornar o seu empreendimento mais atrativo é a liberação de cortesias, para alguns membros do trading turístico e da mídia, de forma a aumentar a simpatia da pousada com o mercado.

No Herbário, além das ervas, há também a venda de artesanato, muitas vezes produzido pelo próprio empreendedor e outras vezes comprado de outros fornecedores, como grupos indígenas. Diferentemente dos remédios, ou das pomadas e xaropes, cuja produção é exclusiva ao Herbário, segundo o empreendedor, por uma questão de garantia. E não há fornecimento desses produtos para outras lojas. O interesse do empreendedor não é expandir o tamanho de seu negócio ou seus ganhos financeiros e sim garantir sua qualidade de vida. A única coisa ainda almejada por Antônio no sentido de crescimento é a aquisição de um pedaço de terra no intuito de desenvolver mais e melhor a parte de cultivo.

A clientela do Herbário são, em sua maioria, turistas. Poucos são os clientes moradores da cidade. Por isso, os melhores ganhos acontecem nas férias ou eventos. Essa alta temporada compensa o período de baixa temporada, controlando assim as receitas e despesas. Outro fator apontado pelo empresário é a inversão percebida por ele no que diz respeito às pessoas do interior e às dos grandes centros urbanos. Segundo Antônio, a 
conscientização sobre o uso das plantas e produtos naturais vem melhorando, entretanto a procura é maior por parte das pessoas dos grandes centros, sendo que as pessoas do interior procuram mais a medicina tradicional. Ou seja, as pessoas que estão mais próximas às plantas acabam dando menor credibilidade a elas.

A produção da empresa Alimentos Orgânicos atualmente abrange barrinhas de cereais, bolos, biscoitos, pães e palitinhos. Há fornecimento desses produtos para outras lojas e restaurantes de produtos naturais e toda a logística fica a cargo do empresário José Moura. Por isso, um dos desejos de José Moura é a aquisição de um caminhão melhor preparado para o transporte desses alimentos, o que ele pretende viabilizar com obtenção de financiamentos,

José Moura afirma também que não é complicada a produção de alimentos mais naturais, mas que há certa complicação no momento de vender, já que o mercado para esse tipo de produto ainda é limitado. Mesmo com ações de promoção dos produtos, o consumo de orgânicos atraem um público restrito, não atraindo, dessa forma, o investimento de grande parte dos varejistas de produtos alimentares, o que muitas vezes encarece esse tipo de produto.

No Santuário a gestão acontece da seguinte forma: o empresário Pedro Souza atua na área de consultoria e cursos, o empreendedor André Souza na área gastronômica e administrativa e a empreendedora Vânia Souza na área financeira.

Atualmente, no Santuário, são feitos 75 produtos e o público está estabilizado em torno de dez mil pessoas por ano. Segundo André, o fator sustentabilidade permite à empresa um leque maior de opções, permite aproveitar as diversas potencialidades naturais do Santuário, com a venda de variados produtos, fazendo com que não haja perda de matéria-prima. Para o empreendedor, um dos segredos está na forma de vender esses produtos, atingindo um maior número de pessoas.

André afirma também que a prestação de serviços no Santuário se torna complexa, devido à flutuação da demanda:

Começamos um turismo de forma correta e errada, errada porque o turista vem na hora que quer, faz o que quer, compra o que quer, tudo é quando quer, e correta porque às vezes o que quer também é gostoso para o turista, ele fazer aquilo, e a gente tem que entender o equilíbrio disso.

Afirma também que uma demanda mais certa proporcionaria uma melhor visão do negócio, definindo melhor os horários e estabelecendo limites à prestação dos serviços.

No caso da pousada Cavalcante, a mídia social tem sido uma das principais ferramentas de promoção. O empreendedor Sérgio Lemes acredita que o fator sustentabilidade contribui sim, e ele almeja dar maior ênfase a esse aspecto.

No que tange à política de preços, Sérgio afirma que ela é elaborada com base em benchmarking, ou seja, através do comparativo com outros empreendimentos de mesmo porte e atuantes no mesmo segmento. O empresário salienta ainda que considera a concorrência em sua região desleal, devido ao alto grau de informalidade, de empresas que não contribuem como deveriam com o governo e a fiscalização é omissa. $E$ devido a esse 
fator, ele afirma que trabalha com uma margem de lucro extremamente reduzida.

À semelhança do que acontece em outras pousadas, na Pousada Cavalcante também há produção de alguns itens, tais como pães, bolos, geleias, biscoitos, iogurtes, polpas de frutas, verduras, temperos. Além disso, a decoração da pousada é também produção artesanal do próprio local.

\section{Principais dificuldades no processo de criação}

As dificuldades identificadas em cada caso ao longo do processo de criação de suas organizações sustentáveis são mostradas no Quadro 4:

Quadro 4: Principais dificuldades detectadas no processo de criação das organizações analisadas.

Chart 4: Major difficulties encountered in the process of creation of organizations analyzed.

\begin{tabular}{|c|c|}
\hline \multicolumn{2}{|r|}{ Principais dificuldades detectadas } \\
\hline Pousada Pirenópolis & $\begin{array}{l}\text { Escassez de recursos financeiros. } \\
\text { Serviços públicos de má qualidade. }\end{array}$ \\
\hline Herbário & $\begin{array}{l}\text { Exigência da vigilância sanitária. } \\
\text { Conhecimento popular sujeito à extinção. }\end{array}$ \\
\hline Santuário & $\begin{array}{l}\text { Baixa qualificação e dificuldades com logística da mão-de-obra. } \\
\text { Processo complexo de certificação. } \\
\text { Desconhecimento prévio do processo produtivo. } \\
\text { Flutuação na demanda. }\end{array}$ \\
\hline Pousada Cavalcante & $\begin{array}{l}\text { Desconhecimento prévio do mercado. } \\
\text { Privacidade limitada. } \\
\text { Falta de ação governamental (na estrutura física, na oferta de subsídios para o de- } \\
\text { senvolvimento regional e na fiscalização de práticas empresariais predatórias). } \\
\text { Posicionamento geográfico desfavorável da cidade (dificuldades na logística e abas- } \\
\text { tecimento). }\end{array}$ \\
\hline $\begin{array}{l}\text { Empresa Alimentos } \\
\text { Orgânicos }\end{array}$ & $\begin{array}{l}\text { Falta de garantias no fornecimento de matéria-prima orgânica por produtores locais. } \\
\text { Falta de interesse das pousadas locais em adquirir produtos orgânicos. } \\
\text { Gargalos no processo produtivo. } \\
\text { Problemas logísticos na entrega dos produtos. }\end{array}$ \\
\hline
\end{tabular}

Fonte: Dados da pesquisa.

Source: Research data.

Pela análise das dificuldades apresentadas nos casos, podemos perceber que estas estão relacionadas a três categorias principais:

Dificuldades com serviços ou políticas públicas. Os obstáculos relacionados indireta ou diretamente ao governo foram citados nos casos da Pousada Pirenópolis, do Herbário, da Pousada Cavalcante e do Santuário. Conforme afirma o empreendedor Fabrício Mendonça, da Pousada Pirenópolis: "As maiores dificuldades que eu tenho como empresário não é nem em relação a eu ser sustentável ou não, são os serviços públicos de péssima qualidade".

Dificuldades relacionadas ao processo logístico ou de produção. Essas dificuldades podem ser observadas: no caso do Santuário, quando citam problemas com a logística da mão de obra e quando ressaltam que o desconhecimento prévio do processo produtivo foi um obstáculo; no caso da Pousada Cavalcante, ao afirmar que há um desfavo- 
rável posicionamento geográfico da cidade que gera dificuldades na logística e abastecimento; e especialmente no caso da empresa Alimentos Orgânicos, ao citar como dificuldades a falta de garantias no fornecimento de matéria-prima orgânica por produtores locais, os gargalos que integram o processo produtivo e os problemas logísticos na entrega dos produtos.

Dificuldades relacionadas à falta de planejamento. As dificuldades citadas nos casos do Santuário - flutuação na demanda - e da Pousada Cavalcante - desconhecimento prévio do mercado - poderiam ter sido solucionados com um planejamento estruturado.

\section{Conclusões}

O objetivo do presente trabalho foi o de analisar o processo de criação de empresas que exploram o nicho da sustentabilidade, as principais atividades que o constituem e as principais dificuldades encontradas pelos empreendedores.

Durante a análise, foi possível observar que as etapas do processo de criação das organizações sustentáveis analisadas ocorreram de uma forma semelhante ao sugerido pelo quadro de análise - Quadro 3 - o que indica a utilidade deste modelo também no nicho da sustentabilidade.

Além disso, foi possível perceber algumas atividades comuns entre as empresas analisadas: em todos os casos, os empreendedores já haviam tido algum tipo de contato com o meio natural, o que contribuiu com o desejo de criar um negócio sustentável; todos almejavam prioritariamente qualidade de vida, eram movidos pela paixão e pela vontade de contribuir com o meio e em nenhum dos casos o interesse era exclusivamente financeiro; no processo de criação, houve poucas atividades de planejamento, assim como poucas práticas estruturadas de promoção do empreendimento.

Observa-se também que além da adoção de práticas sustentáveis, tais como reflorestamento, reciclagem e educação ambiental, como nos casos da pousada Pirenópolis e do Santuário, há também uma preocupação no que diz respeito à responsabilidade social, representada no bom trato dos funcionários, relatado especificamente nos casos da pousada Pirenópolis, onde os funcionários são motivados à conscientização ambiental através da participação nos lucros advindos de materiais reciclados, e na pousada Cavalcante, que adota várias políticas de motivação e qualificação, entre elas a política de hospedar os funcionários na pousada, dando-lhes acesso gratuito aos serviços.

As principais dificuldades encontradas nos casos foram categorizadas da seguinte forma: dificuldades com serviços ou políticas públicas; dificuldades relacionadas ao processo logístico ou de produção; dificuldades relacionadas à falta de planejamento.

Os resultados obtidos com a pesquisa, através da reconstrução do processo de criação dos casos selecionados e posterior identificação das dificuldades presentes nesse processo, contribuem para facilitar e estimular a ação dos empreendedores sustentáveis em potencial, esclarecendo-os quanto ao processo que percorrerão para realizar a criação de sua organização, quais os principais desafios que encontrarão nesse processo, para que possam melhor se preparar na busca de soluções. Os resultados auxiliam também os gestores públicos a repensarem suas ações e a reformularem as políticas que vem sendo implantadas em favorecimento ao empreendedorismo sustentável. 
Para futuros estudos, sugere-se a abordagem da temática de políticas públicas voltadas ao setor de turismo, assim como a continuidade e maior aprofundamento da presente pesquisa, através da análise de mais casos do setor turístico.

\section{Referências bibliográficas}

BARBIERI, J.C.; VASCONCELLOS, I.F.G.; ANDREASSI, T.; VASCONCELOS, F.C. Inovação e sustentabilidade: novos modelos e proposições. RAE - Revista de Administração de Empresas, v. 50, n. 2, p. 146-154, abr./jun. 2010.

BORGES, C.; FILION, L. J.; SIMARD, G. Jovens Empreendedores e o processo de criação de empresas. RAM - Revista de Administração Mackenzie, Universidade Presbiteriana Mackenzie, v. 9, n. 8, nov./dez. 2008. Edição especial.

BORGES, C.; BORGES, M.M.; FERREIRA, V.R.S.; NAJBERG, E.; TETE, M.F. Empreendedorismo sustentável: proposição de uma tipologia e sugestões de pesquisa. ENCONTRO DA ANPAD, 35, 2011, Rio de Janeiro. Anais... Rio de Janeiro: ANPAD, 2011.

BOSZCZOWSKI, A. K.; TEIXEIRA, R. O empreendedorismo sustentável e o processo empreendedor: em busca de oportunidades de novos negócios como solução para problemas sociais e ambientais. ENCONTRO DA ANPAD, 33, 2009, São Paulo. Anais... São Paulo: ANPAD, 2009.

COSTA, F.J. Fatores de influência no interesse empreendedor: uma análise junto a estudantes de Turismo. Revista Brasileira de Pesquisa em Turismo, v.2, p.4-27, 2008.

DALMORO, M. A visão da sustentabilidade na atividade empreendedora: uma análise a partir de empresas incubadas. Revista Gestão Organizacional, v. 2, n. 1, p. 87-104, jan./ jun. 2009.

DEHEINZELIN, L. Economia criativa e empreendedorismo cultural. In: ENCONTRO DE ESTUDOS MULTIDISCIPLINARES EM CULTURA, 2., 2006, Salvador. Anais... Salvador: CULT, 2006.

DIXON, S.E.A.; CLIFFORD, A. Ecopreneurship - a new approach to managing the triple bottom line. Journal of Organizational Change Management, v. 20, n. 3, p. 326-345, 2007.

ELKINGTON, J. Cannibals with forks: the triple bottom line of 21st century business. Oxford, UK: Capstone Publishing Limited, 1998.

FILION, L.J. Empreendedorismo: empreendedores e proprietários-gerentes de pequenos negócios. Revista da Administração, v. 34, n. 2, abr./jun., p.05-28, 1999.

HISRICH, R.D.; PETERS, M.P.; SHEPHERD, D.A. Empreendedorismo. Porto Alegre: Bookman, 2009.

HOCKERTS, K.; WÜSTENHAGEN, R. Greening Goliaths versus emerging Davids: theorizing about the role of incumbents and new entrants in sustainable entrepreneurship. Journal of Business Venturing, v. 25, p. 481-492, 2010.

INSTITUTO ETHOS. O que é RSE. Disponível em: <http://www1.ethos.org.br/EthosWeb/ pt/ 29/o que e rse/o que e rse.aspx>. Acesso em: 21 set. 2012. 
LIMEIRA, T.M.V. Empreendedor cultural: perfil e formação profissional. In: ENCONTRO DE ESTUDOS MULTIDISCIPLINARES EM CULTURA, 4., 2008, Salvador. Anais... Salvador: CULT, 2008.

MACHADO, H.; MACHADO, H.V.; ST-CYR, L.; MIONE, A.; ALVES, M.C.M. O processo de criação de empresas por mulheres. RAE eletrônica, v. 2, n. 2, jul./dez. 2003. Disponível em <http://www.scielo.br/pdf/raeel/v2n2/v2n2a07.pdf>. Acesso em: 21 set. 2012.

MAIR, J; MARTI, I. Social entrepreneurship research: a source of explanation, prediction, and delight. Journal of World Business, v. 41, p. 36-44, 2006.

MELO NETO, F.P.; FROES, C. Empreendedorismo Social: a transição para a sociedade sustentável. Rio de Janeiro: Qualitymark, 2002.

MELO, L.J.; COHEN, M. Empreendimentos inovadores, nova mentalidade? Um estudo exploratório sobre a sustentabilidade empresarial em uma incubadora de empresas. In: ENCONTRO DE ESTUDOS EM ESTRATÉGIA, 4., 2009, Recife. Anais... Recife: ANPAD, 2009.

MILES, M. B.; HUBERMAN, A. M. Qualitative data analysis: an expanded sourcebook. Thousand Oaks, Calif: Sage, 1994.

MORETTO, C.F.; GIACCHINI, J. Do surgimento da teoria do desenvolvimento à concepção de sustentabilidade: velhos e novos enfoques rumo ao desenvolvimento sustentável. In: ENCONTRO DO ECOECO, 6., 2005, Brasília. Anais... Brasília: UnB, 2005. CD-ROM.

NASCIMENTO, E. P. Trajetória da sustentabilidade: do ambiental ao social, do social ao econômico. Estudos avançados, v. 26, n. 74, 2012.

ONOZATO, E.; TEIXEIRA, R. . Processo de criação de organizações com fins sociais: estudo de casos múltiplos na cidade de Curitiba - Paraná. In: ENCONTRO DE ESTUDOS SOBRE EMPREENDEDORISMO E GESTÃO DE PEQUENAS EMPRESAS, 5., 2008, São Paulo. Anais... São Paulo: 2008. CD-ROM.

PARRISH, B.D. Sustainability entrepreneurship: design principles, processes, and paradigms. Leeds, UK: University of Leeds, 2007.

PIMENTEL, T.A.B.; REINALDO, H.O.A.; OLIVEIRA, L.G.L. Empreendedorismo sustentável: uma análise da implementação da sustentabilidade empresarial em micro, pequenas e médias empresas industriais atendidas pelo PEIEX - no NUTEC. In: SIMPÓSIO DE ADMINISTRAÇÃO DA PRODUÇÃO, LOGÍSTICA E OPERAÇÕES INTERNACIONAIS, 13., 2010, São Paulo. Anais... São Paulo: FGV, 2010.

SCHALTEGGER, S. A Framework for Ecopreneurship. Greener Management International, v. 38, p. 45-58, 2002.

SCHARF, R. Manual de negócios sustentáveis. Como aliar rentabilidade e meio ambiente. São Paulo: Amigos da Terra - Amazônia Brasileira; Fundação Getúlio Vargas, Centro de Estudos em Sustentabilidade, 2004.

SHANE, S. Technological opportunities and new firm creation. Management Science, v. 47, n. 2, p. 205-220, fev. 2001. 
SHANE, S.; VENKATARAMAN, S. The promise of entrepreneurship as a field of research. Academy of Management Review, v. 25, n. 1, p. 217-226, 2000.

SHEPHERD, D.A.; PATZELT, H. The new field of sustainable entrepreneurship: studying entrepreneurial action linking "what is to be sustained" with "what is to be developed". Entrepreneurship Theory and Practice, v. 35, n. 1, p. 137-163, jan. 2011.

TEIXEIRA, R.M. Desempenho e obstáculos ao crescimento de pequenos negócios hoteleiros em Curitiba. Revista Turismo Visão e Ação - Eletrônica, v.14, n. 1, p. 99-117, jan./abr. 2012. Disponível em: < http://siaiweb06.univali.br/seer/index.php/rtva/article/ view/26 96/2169>. Acesso em: 21 set. 2012.

YIN, R.K. Estudo de caso - planejamento e métodos. Porto Alegre: Bookman, 2005.

YOUNG, W.; TILLEY, F. Can businesses move beyond efficiency? The shift toward effectiveness and equity in the corporate sustainability debate. Business Strategy and the

Environment, v. 6, n. 15, p. 402-415, 2006.

\section{Agradecimento:}

Os autores agradecem ao Conselho Nacional de Desenvolvimento Científico e Tecnológico (CNPq), agência do Ministério da Ciência, Tecnologia e Inovação (MCTI) do Brasil, pelo apoio na realização da pesquisa que subsidiou este artigo.

Thaynara Santiago Pereira: Universidade Federal de Goiás, Goiânia, GO, Brasil.

Email: thaynarasantiago@gmail.com

Link para o currículo Lattes: http://lattes.cnpq.br/9462573744575800

Cândido Borges: Universidade Federal de Goiás, Goiânia, GO, Brasil.

Email: candidoborges@gmail.com

Link para o currículo Lattes: http://lattes.cnpq.br/4803860037213326

Data de submissão: 13 de outubro de 2012

Data de recebimento de correções: 13 de outubro de 2012

Data do aceite: 04 de julho de 2013

Avaliado anonimamente 